\title{
Proven Performance: Aged TPO Field Study
}

\author{
Jennifer Keegan ${ }^{1}$, Thomas J. Taylor ${ }^{2}$ and James R. Kirby ${ }^{3}$ \\ ${ }^{1}$ Director, Building and Roofing Science at GAF, 1 Campus Drive, Parsippany, NJ 07054, USA, \\ jennifer.keegan@gaf.com \\ ${ }^{2}$ Building and Roofing Science Advisor at GAF, 1 Campus Drive, Parsippany, NJ 07054, USA, \\ thomas.taylor@gaf.com \\ ${ }^{3}$ Building and Roofing Science Architect at GAF, 1 Campus Drive, Parsippany, NJ 07054, USA, \\ james.kirby@gaf.com
}

\begin{abstract}
New thermoplastic polyolefin (TPO) roof membranes have been extensively analyzed in laboratories, roof exposure farm fields, and under accelerated weathering conditions. The ASTM International material standard specification for TPO membranes has been regularly improved since its inception to incorporate more demanding tested-product performance, including requirements for accelerated weathering and aging. Industry data on the aged performance of TPO roof membranes to date has largely been based on laboratory work, regional studies, and anecdotal case studies of TPO roofs, predominantly those that have been improperly designed and/or installed, and membranes with retired formulations that resulted in premature failure. Today, there are TPO roofs in the United States that have been in service for nearly 20 years. This paper will review the long-term performance of a large sampling of TPO roof membranes installed throughout the United States by evaluating thickness, flexibility, inspection under $7 X$ magnification, aged seam strength, and repair weld adhesion. The intent of this study was to evaluate 1) field-aged TPO roof membrane performance and 2) the ability to repair field-aged TPO roof membranes.
\end{abstract}

Keywords: TPO, FPO, Aged Performance, Field-Study, Long-Term Performance, Repairability.

\section{Introduction}

Flexible Polyolefin (FPO) roof membranes have been part of the European roofing market since the late 1980 's. In the early 1990's, this technology migrated to the United States as Thermoplastic Polyolefin (TPO). FPO and TPO are the same polymer that use different terminology in the European and United States markets, respectively, and will be referred to as TPO throughout this paper.

TPO roof membranes are the fastest growing commercial roof membrane on the market, and has grown significantly over the past 20 years. According to the European Single Ply Waterproofing Association (ESWA), TPO is growing in market share, and according to the Single Ply Roofing Institute, TPO represents almost half of the installed low-slope roofing in the United States. The global TPO roof membrane market is expected to reach $\$ 2.2$ billion by 2024, with a compound annual growth rate (CAGR) of 3.7-percent from 2019 to 2024 (ResearchAndMarkets, 2019). 
These membranes are now regarded as a mature technology with properties defined by the ASTM International material standard for TPO membranes, ASTM D6878. These standards have been improved since their inception to incorporate more demanding tested-product performance, including stronger requirements for accelerated weathering and aging.

Today, there are TPO roofs that have been in service for over 20 years (ASTM D573; Taylor and Xing, 2015). This paper reviews the long term performance of field-aged TPO roof membranes to assess performance and the ability to repair aged TPO roof membranes. Specifically addressed are known failure modes of some manufactured TPO membranes which include erosion of the cap (thickness over scrim) down to the scrim and surface cracking, as well as concerns surrounding the ability to repair aging TPO membranes.

\section{Program}

The intent of this study was to evaluate field-aged TPO roof membrane performance and the ability to repair membranes as they age. Membrane samples were collected from roofs around the United States that were at least 12 years in service. Roofs were selected to gain a general sense of typical performance in various locations across the country. Most of the roofs evaluated to date in this study were installed between 2005 and 2006; the oldest sample reviewed to date was installed 18 years ago. All samples were from the same manufacturer

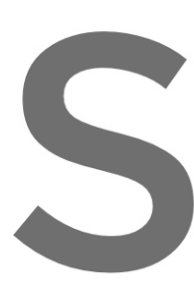
and were predominant membranes. Samples roofs. Self-adhered membrane

2.1 Sample Selection
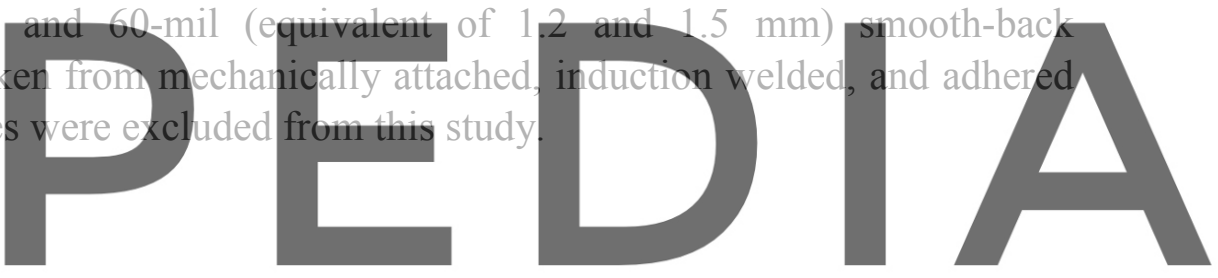

Each Samples approximately $60 \mathrm{~cm}$ by $90 \mathrm{~cm}$ (2-foot by 3-foot) and captured a field-welded

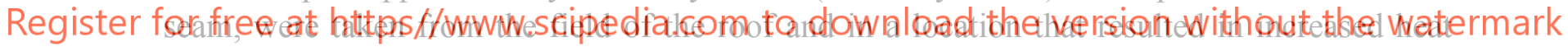
exposure.

The large samples were cut into smaller pieces to evaluate membrane thickness, thickness over scrim, brittleness, heat aging and weather resistance, ply adhesion of existing welds, and ply adhesion of repair welds. Each test was conducted on five unique specimens from each location on the roof.

\subsection{Test Program}

The testing program was built around ASTM D6878-19, with modifications as needed for aged samples. The artificial aging tests were replaced with field aging for a minimum of 12 years. All tests were conducted in a commercial test laboratory. All data gathered was used in the analysis. 


\subsubsection{Membrane Thickness and Thickness of Coating Over Scrim}

TPO membranes consist of two polymer layers of TPO, the cap and the core, which are laminated together with a polyester reinforcing scrim in-between. Following ASTM D751 and ASTMD7635/D7635M respectively, the overall membrane thickness and the thickness of the coating over the scrim (or cap layer) was measured. This measurement was compared to the current ASTM TPO standard requirements for new membranes to evaluate how they are weathering.

\subsubsection{Heat Aging and Weather Resistance}

ASTM D6878-19 requires 56 days of heat aging or a radiant exposure of $10,080 \mathrm{~kJ} /\left(\mathrm{m}^{2} . \mathrm{nm}\right)$ prior to the mandrel bend and inspection. As the membrane samples were already aged, the artificial UV and heat aging exposures were eliminated from the test protocol and the pass/fail requirements were applied to the field aged materials.

Heat aging and weather resistance are evaluated per ASTM D573 and ASTM G151/G155 respectively, which includes an inspection at $7 \mathrm{X}$ magnification when bent over a 3-inch diameter mandrel for surface cracking.

\subsubsection{Low Temperature Flexibility}
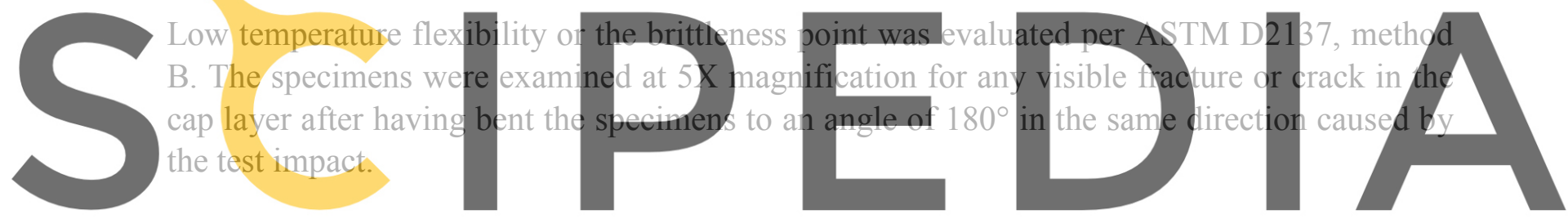

2.2.4 Aged Ply Adhesion

Register for free at https//www.scipedia.com to download the version without the watermark

adhesion. The ply adhesion values reported are the average of the maximum load values at the initial break.

Ply adhesion testing of a proper weld will fail cohesively within one of the plies, exposing the underlying scrim. This is called a "film tearing bond" and is also used to evaluate the integrity of the weld. For the purposes of this evaluation, anything over 70-percent film tearing bond was considered a proper weld.

\subsubsection{Repair Ply Adhesion}

New TPO membrane that was commensurate in type and thickness of the existing membrane, was welded to the aged membrane to evaluate the ability to repair aged materials. Repairs with new membrane welded to the cap of the aged membrane were evaluated, as well as new material welded to the core (the underside) of the aged membrane. Ply adhesion to the core was not evaluated for adhered membrane samples due to remnants of adhesive and/or facer 
from the insulation or cover board. Given the remnants attached to the underside of adhered membranes, repairs to the core would not be reliable.

\section{Data Analysis}

Samples were taken from 20 different roofs across the United States (See Figure 1). Climatic conditions of the United States cities were matched up with their European counterparts, and are shown in Figure 2 to illustrate the approximate European climate equivalents captured in this study. These roofs were installed over office buildings, manufacturing facilities, retail outlets, libraries, automotive repair shops, warehouses, and a grocery store. All data gathered was used in the analysis.

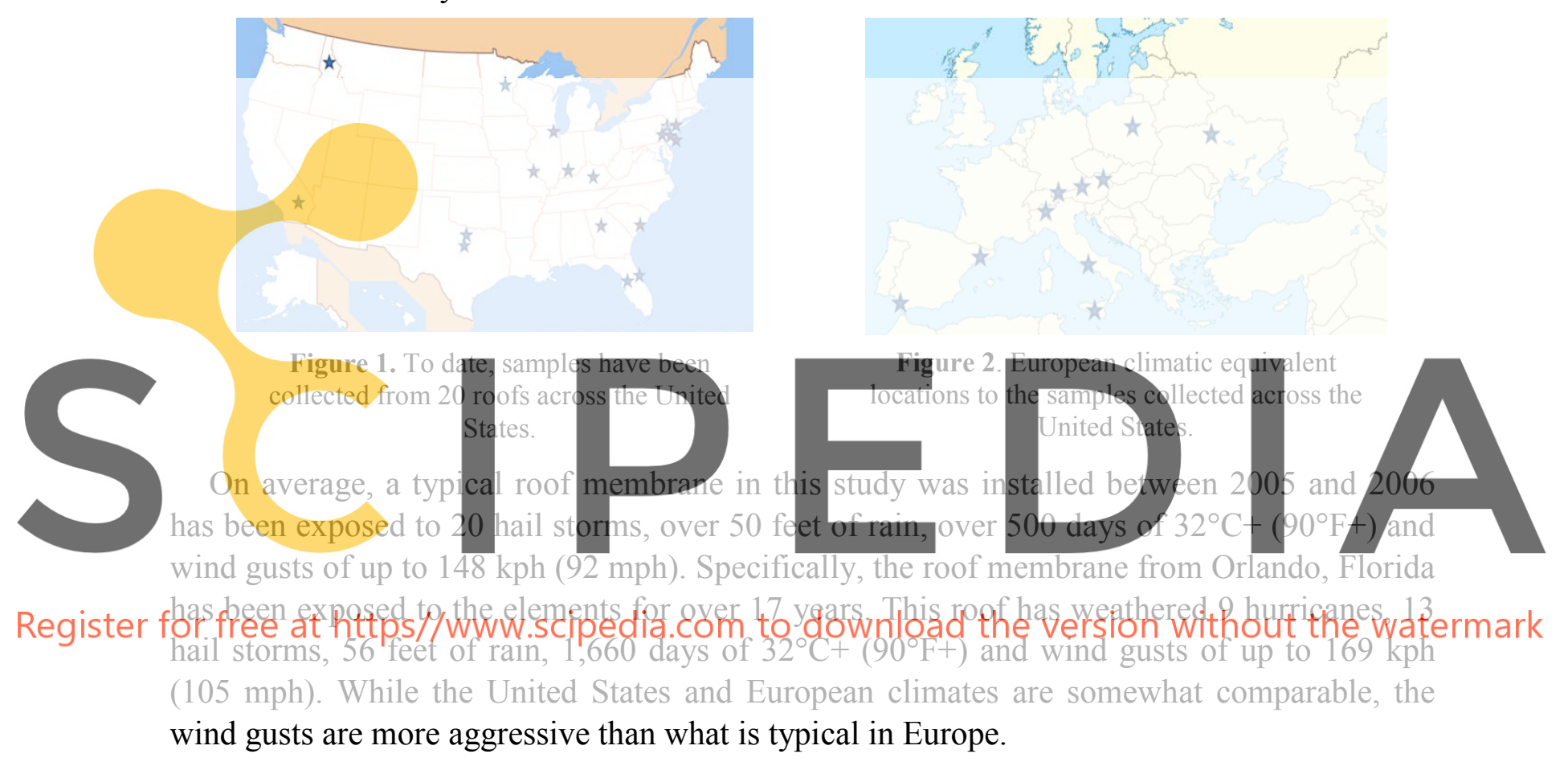

\subsection{Membrane Thickness and Thickness of Coating over Scrim}

Retention of the cap material, i.e. the thickness over scrim, is critical to the membrane's longterm performance as it provides the UV and heat stabilization properties of the membrane. As the cap erodes, the scrim can become exposed and the weather tightness of the membrane is then compromised.

The analysis of aged roof samples began with overall membrane thickness. ASTM standard D6878-19 requires the as-produced membrane to be within $+15 \%,-10 \%$ of stated thickness, and not less than 39-mils. Even after 12 or more years of aging, all of the 45 and 60 -mil (1.2mm and $1.5 \mathrm{~mm}$ equivalent) membrane samples complied with the current ASTM requirements for newly manufactured TPO membranes. 
ASTM standard D6878-03, the active specification at the time the sampled roofs were installed, required $12-\mathrm{mil}(0.30 \mathrm{~mm})$ thickness over scrim. The current version of this standard requires the thickness over scrim to be at least 30-percent of the overall membrane thickness and not less than 18 -mils $(0.45 \mathrm{~mm})$. Both the 45 and 60 -mil (1.2mm and $1.5 \mathrm{~mm}$ equivalent) membranes analyzed in this study are still in compliance with the newly manufactured membrane requirements and are even in compliance with the current standard ASTM D687819, with the thickness over scrim exceeding ASTM minimums and averaging 37- to 40percent of the nominal membrane thickness. The 45 -mil $(1.2 \mathrm{~mm})$ samples averaged 18 -mils $(0.45 \mathrm{~mm})$ over scrim and the 60 -mils $(1.5 \mathrm{~mm})$ samples averaged 22 -mils $(0.56 \mathrm{~mm})$ over scrim. It should be noted that the EN 13956-12 does not include thickness over scrim measurements.

\subsection{Heat Aging and Weather Resistance}

Surface cracking was evaluated by visual inspection of the roof membranes at the time the samples were collected, and through modified versions of heat aging and weather resistance testing. Both ASTM tests require inspection at 7X magnification when bent over a 7.6mm (3inch) diameter mandrel. As the samples were field aged for a minimum of 12 years artificial heat aging and weathering were eliminated, and a focus placed on visual assessment. This evaluation is an important indicator of long term performance (Taylor and Xing, 2015 ), Surface cracking can le long term performance $1.5 \mathrm{~mm}$ equivalent) ment and viewed at $7 \mathrm{X}$ magnification.
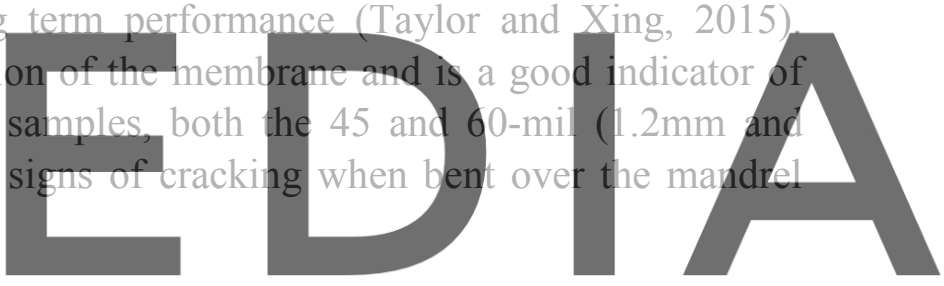

3.3 Low Temperature Flexibility

Register for free at https//WwW.scipedia.com to download the version without the watermark The aged roof samples were evaluated for low temperature flexibility to determine if the membrane became more brittle and prone to cracking as it aged. ASTM standard D6878-19 requires new membranes to have a brittleness point of $-40^{\circ} \mathrm{C}\left(-40^{\circ} \mathrm{F}\right)$ or lower. All of the 60 mil $(1.5 \mathrm{~mm})$ samples tested to date still met this requirement after 12 or more years of field aging. The $45-\mathrm{mil}(1.2 \mathrm{~mm})$ samples showed signs of cracking at $-37^{\circ} \mathrm{C}\left(-35^{\circ} \mathrm{F}\right)$. While this is still good performance and aged membranes cannot be expected to perform at the same level as new membranes, the data does support the use of thicker membranes for longer term performance.

\subsection{Aged Ply Adhesion and Repair Ply Adhesion}

The ply adhesion of the aged samples averaged approximately $8.76 \mathrm{~N} / \mathrm{mm}(50 \mathrm{lbf} / \mathrm{in}$.) for both the 45 and 60 -mil (1.2mm and $1.5 \mathrm{~mm}$ equivalent) membranes, with a minimum of 70 -percent film tearing bond. Representative data are shown in Figure 14. Ply adhesion of TPO membranes should be evaluated throughout the day during installation. The film tearing bond sample is evaluated to confirm the membrane is properly welded together. If the sample fails 
and the scrim is not exposed, or the film tearing bond is not greater than 70-percent, the contractor must adjust the heat and/or speed at which the welding equipment is being used. While failures associated with welded seam delamination are not common, and poor welds are generally identified during routine inspections during installation, ply adhesion is used as a quality control tool in the field. However, there is not a clear industry consensus on the minimum strength requirement to evaluate ply adhesion.

New TPO membrane samples included in a broad TPO sampling study of all industry manufacturers conducted by Structural Research, Inc. (SRI) (Dupuis, 2019) averaged a ply adhesion (T-Peel) value of $7.01 \mathrm{~N} / \mathrm{mm}$ (40 lbf/in.), with a minimum value of $5.13 \mathrm{~N} / \mathrm{mm}(29.3$ lbf/in.) However previously, (Simmons et al., 1999) found that the ply adhesion tests typically failed adhesively, meaning there was not a strong bond between the TPO layers, when the ply adhesion was $4.55 \mathrm{~N} / \mathrm{mm}$ (26 lbf/in.) or less. Simmons findings supports SRI's minimum value threshold for ply adhesion. The ply adhesion values of the aged TPO membranes were 15-percent above the average ply adhesion value from the SRI study on new TPO membranes. Therefore, as expected, the aged welds appear to be performing well and are of adequate strength. To address questions around the ability to repair aged TPO membranes, this study examined the adhesion of new membrane to aged membrane. Two approaches were examined; welding the new membrane to the cap of the aged membrane, and new membrane welded to the core of the aged membrane.

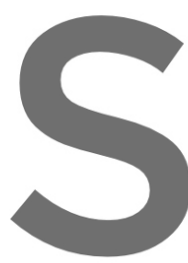

The ply adhesion 45-mil (1.2mm) memb the new membrane wel and $9.98 \mathrm{~N} / \mathrm{mm}(57 \mathrm{lbf} / \mathrm{in}$. membranes, respectivel
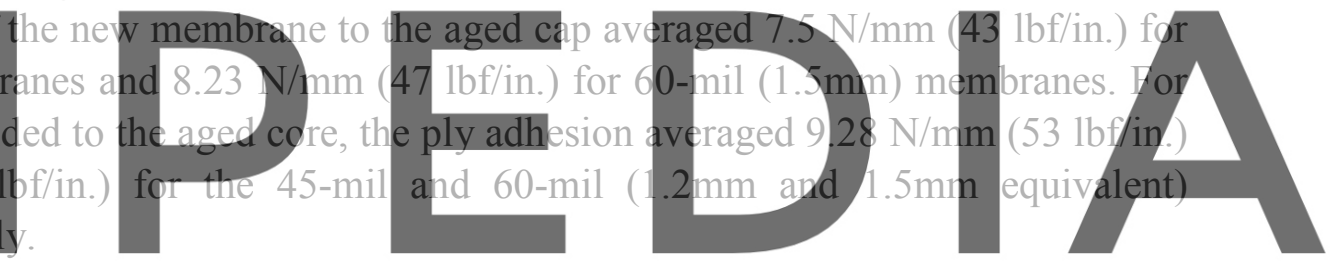

The ply adhesion values of new repair membrane to the aged TPO membrane are above the

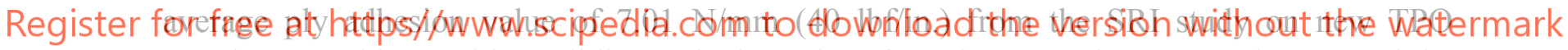
membranes. This provides validity to the integrity of repairs to aged TPO membranes and the ongoing maintainability of these roofs.

\section{Next Steps and Interim Conclusions}

While this paper summarizes data from 20 different roofs from around the country, samples will continue to be collected and analyzed. It is noted that all data received to date has been included in this analysis. No data detrimental or otherwise has been excluded from the analysis or findings.

The findings to date, as summarized in Figure 3, illustrate the robust performance of TPO membranes as they age. Given the inherent flexibility and fungal resistance of TPO, and the UV and heat stabilizers, this comes as no surprise. However, the ability to repair aged TPO membranes has been undefined and anecdotal to date. The interim findings of this study clearly demonstrate the weld integrity of properly executed repairs. 
While this study is focused on TPO membranes the United States, this evaluation only strengthens the findings of previous studies on the durability and repairability of TPO roof membranes in Europe.

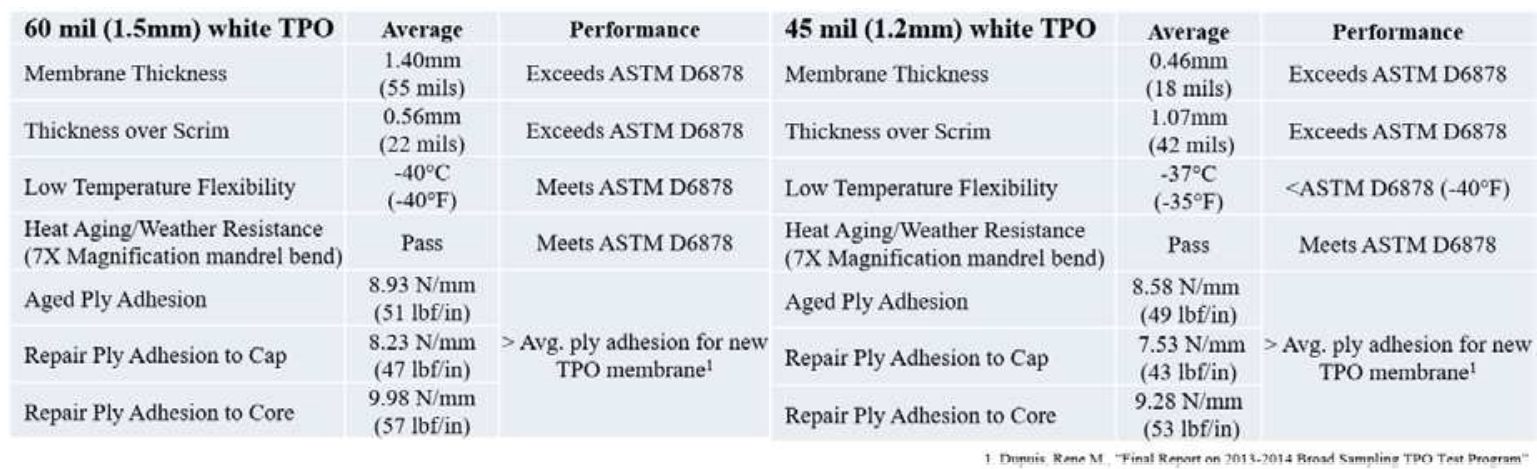

Figure 3. Average findings from study to date for 45 and 60-mil (1.2mm and 1.5mm equivalent) membranes as compared to ASTM D6878-19.

\section{Conclusion}

In summary, the aged TPO membrane roofs in this study are performing well and in most

instances, meeting the current ASTM D6878-19 requirements for newly manufactured

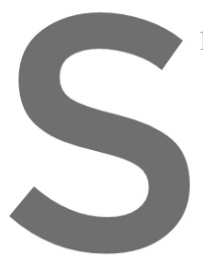

membranes.

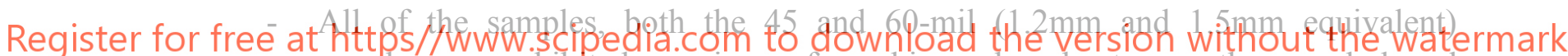
menbranes, exhiblted no signs of cracking when bent over the mandrel and viewed at 7X magnification.

- All of the 60-mil $(1.5 \mathrm{~mm})$ samples tested to date still meet cold temperature flexibility requirements of $-40^{\circ} \mathrm{C}\left(-40^{\circ} \mathrm{F}\right)$ after 12 or more years of aging. The $45-$ mil $(1.2 \mathrm{~mm})$ samples showed signs of cracking at $-37^{\circ} \mathrm{C}\left(-35^{\circ} \mathrm{F}\right)$.

- Ply adhesion values of new repair membrane to the aged TPO membrane are above the average for new TPO membranes. This provides some validity to the integrity of properly executed repairs to aged TPO membranes.

\section{Acknowledgements}

The authors would like to thank Christopher McGroarty, Greg Coletto, Jim Brikla, Mark Anderson, and Joshua Wilson for their assistance in this research initiative.

\section{References}

ASTM D573. Standard Test Method for Rubber-Deterioration in an Air Oven. ASTM D751. Test Methods for Coated Fabrics. 
ASTM D7635/D7635M. Standard Test Method for Measurement of Thickness of Coatings Over Fabric Reinforcement.

ASTM D1876 - 08. Standard Test Method for Peel Resistance of Adhesives.

ASTM D2137. Standard Test Methods for Rubber Property_Brittleness Point of Flexible Polymers and Coated Fabrics.

ASTM G151. Standard Practice for Exposing Nonmetallic Materials in Accelerated Test Devices that Use Laboratory Light Sources.

ASTM G155 Standard Practice for Operating Xenon Arc Light Apparatus for Exposure of Non-Metallic Materials.

Beer, H.R. et al. (2011). Longterm Field Studies and Residual Service Life Prediction of FPO Roofing Membranes, DBMC XII.

Croce, S. and Fiori, M. (2008). Polyolefin Roof Membranes On Site Durability Evaluation, 11th International Conference on Durability of Building Materials and Components, Istanbul, Turkey, May $11^{\text {th }}-14^{\text {th }}$.

Dupuis, R.M. (2019). Final Report on 2013-2014 Broad Sampling TPO Test Program, 2015, 1-7.

European Single ply Waterproofing Association Roofing, page: https://www.eswa.be/roofing.cfm as stated on website as seen on October 14, 2019.

Pierce, H.H. and Xing, L. (2017). Understanding Accelerated UV, Field and Thermal Aging of Thermoplastic Roofing Membranes, XIV DMBC 2017.

ResearchAndMarkets.com, TPO Roofing Membrane Market Report: Trends, Forecast and Competitive Analysis July 2019

Simmons, T.R., Runyan, D., Liu, K.K.Y., Paroli, R.M., Delgado, A.H. and Irwin, J.D. (1999). Effects of Welding Parameters on Seam Strength of Thermoplastic Polyolefin (TPO) Roofing Membranes, Proceedings of the North American Conference on Roofing Technology, 56-65.

Taylor, T.J. (2015). The History of TPO and How it Has Changed the Commercial Roofing Market, Florida Roofing, 10-11

Taylor, T.J. and Xing, L. (2015). Actual Performance, Molleti (West Conshohocken, PA

Western States Roofing Update Report, 1-18.
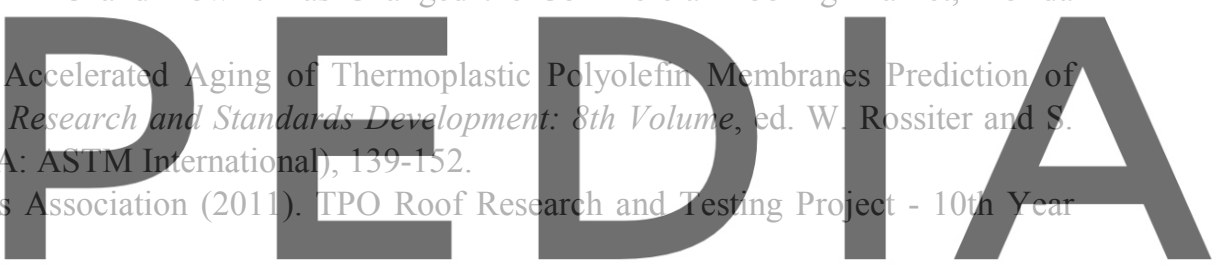